\title{
Gender differences among patients admitted following poisoning: a prospective study in Southern Sri Lanka
}

\author{
MCB Galahitiyawa ${ }^{1}$, MRP Weerawansa ${ }^{1}$, JDVC Lekamwasam ${ }^{2}$ \\ ${ }^{1}$ Registrar in Medicine, ${ }^{2}$ Consultant Physician, Teaching Hospital Karapitiya, Galle
}

\begin{abstract}
Objective: To examine gender differences among subjects admitted following poisoning in Southern, Sri Lanka.

Setting: Teaching Hospital, Karapitiya, Galle.

Materials and Methods: 303 consecutive patients, admitted to Teaching Hospital, Karapitiya following self ingestion of poisons, from April to September 2006 were included in the study. All were interviewed during their hospital stay and data were collected using a pre-designed questionnaire.

Results: There were 135 males (44.55\%). Median (IQR) ages of males and females were 24(19-36) and $21(18-26)$ years respectively $(\mathrm{p}<0.001) .43 \%$ of males had only primary education whereas $82 \%$ of females had education above $\mathrm{O} / \mathrm{L}(\mathrm{p}<0.001) .65 .9 \%$ males and $40.5 \%$ females were unemployed $(\mathrm{p}<0.001) .51 .1 \%$ of males were from social class 5 (the lowest) whereas $43.5 \%$ of females were from one social class above, $4(\mathrm{p}=0.005)$. Family conflicts were the immediate cause of poisoning in $57.1 \%$ females and $40 \%$ males $(\mathrm{p}=0.005) .61 .3 \%$ of females presented with drug overdose whereas $61.5 \%$ males had taken agrochemicals $(\mathrm{p}<0.001)$.
\end{abstract}

Conclusions: In this study, compared to women, men who got admitted following poisoning were less educated, unemployed, had high agrochemical use, and came from a lower social class. In the community level, these characteristics can be used in recognizing vulnerable individuals for poisoning. Further, this study highlights the importance of community based programmes to improve the family harmony to reduce the burden of self poisoning.

\section{Introduction}

Deliberate self-harm is a major problem in the developing world and was responsible for around 600,000 deaths in $1990^{1}$. Sri Lanka is a developing agricultural country which has a high fatality rate due to self-poisoning. Very toxic agrochemicals are the main poisoning agents ${ }^{2}$. Although pesticides are the most important poison throughout the tropics, being both common and associated with a high mortality rate, there are other methods used such as drug overdose and plant poisons. Prompt treatment of subjects admitted following poisoning is the main method of reducing morbidity and mortality in Sri Lanka. Psychiatric assessment of patients admitted following poisoning is made routinely to recognize high risk individuals. However, recognition of high risk individuals before the act would be the most effective way of reducing mortality and morbidity associated with poisoning. This is not done as the characteristics of these subjects are not well known. This study addresses the gender differences and other socioeconomic characteristics related to self poisoning in southern Sri Lanka.

\section{Objectives}

1. To study the gender differences among the subjects admitted following self ingestion of poisons.

2. To recognize characteristics to identify vulnerable individuals for poisoning in the society to enroll them in community based counseling programmes. 


\section{Materials and Methods}

The study sample was 303 consecutive patients, admitted to Teaching Hospital Karapitiya following self ingestion of poisons, from April to September 2006. All were interviewed either on admission or when they were stable during their hospital stay. Subjects admitted with accidental poisoning were excluded from the study $(\mathrm{n}=20)$. The interviewers were not involved in the active management of the patients.

Data were collected using a pre-designed questionnaire which was formulated following a pilot study. Demographic data including sex, age, level of education, social class, immediate reason for poisoning, type of poison used, marital status (unmarried, married or divorced), intension of poisoning (suicidal, to threat) and the substance abuse (smoking, alcohol, other) constituted the components of the questionnaire. Social classes were determined according to the British classification of social classes ${ }^{3}$. No personnel identifiers were collected. SPSS for Windows (version 10) was used for the data analysis and $p<0.05$ was taken as the level of statistical significance.

\section{Results}

A total of 303 patients were included in the study and 135 of them were males. The socioeconomic variables examined were compared according to gender using Chi-square trend. Males were older than females (median of 24 vs 21 years, respectively and $\mathrm{P}<0.001$ ). $43 \%$ of males had only primary education or below, whereas $82 \%$ of females had education above primary level $(\mathrm{p}<0.001)$. Majority of males $(65.9 \%)$ and $40.5 \%$ females were currently unemployed $(\mathrm{p}<0.001) .51 .1 \%$ of males were from social class 5 (the lowest) whereas $43.5 \%$ of females were from one social class above, 4 $(\mathrm{p}=0.005)$. Family conflicts were the immediate cause of poisoning in $57.1 \%$ females and $40 \%$ males $(p=0.005) .61 .3 \%$ of females presented with drug over dose whereas $61.5 \%$ males had taken agrochemicals $(\mathrm{p}<0.001)$. These data are shown in Table 1.

Table 1 - Age and socioeconomic characteristics of 303 patients admitted following poisoning

\begin{tabular}{|c|c|c|c|}
\hline \multirow[b]{2}{*}{ Variable } & \multicolumn{2}{|c|}{ Gender } & \multirow[b]{2}{*}{ Significance } \\
\hline & Male $(n=135)$ & Female (n-168) & \\
\hline Median age (IQR) & $24(19-36)$ years & $21(18-26)$ years & $\mathrm{P}<0.001$ \\
\hline $\begin{array}{l}\text { Level of Education } \\
\text { Primary or below } \\
\text { Secondary or above }\end{array}$ & $\begin{array}{l}58(43 \%) \\
77(57 \%)\end{array}$ & $\begin{array}{l}30(17.9 \%) \\
138(82.1 \%)\end{array}$ & $\mathrm{P}<0.001$ \\
\hline $\begin{array}{l}\text { Current employment } \\
\text { Employed } \\
\text { Unemployed }\end{array}$ & $\begin{array}{l}46(34.1 \%) \\
89(65.9 \%) \\
\end{array}$ & $\begin{array}{l}100(59.5 \%) \\
68(40.5 \%)\end{array}$ & $\mathrm{P}<0.001$ \\
\hline $\begin{array}{l}\text { Social class } \\
1,2 \& 3 \\
4 \\
5 \\
\end{array}$ & $\begin{array}{l}17(12.6 \%) \\
49(36.3 \%) \\
69(51.1 \%) \\
\end{array}$ & $\begin{array}{l}37(22.0 \%) \\
73(43.5 \%) \\
58(34.5 \%) \\
\end{array}$ & $\mathrm{P}<0.008$ \\
\hline $\begin{array}{l}\text { Immediate reason } \\
\text { Family conflicts } \\
\text { Other causes }\end{array}$ & $\begin{array}{l}54(40.0 \%) \\
81(60.0 \%) \\
\end{array}$ & $\begin{array}{l}96(57.1 \%) \\
72(42.9 \%)\end{array}$ & $\mathrm{P}<0.005$ \\
\hline $\begin{array}{l}\text { Type of poison } \\
\text { Drug overdose } \\
\text { Agrochemicals } \\
\text { Other }\end{array}$ & $\begin{array}{l}42(31.1 \%) \\
83(61.5 \%) \\
10(07.4 \%)\end{array}$ & $\begin{array}{l}103(61.3 \%) \\
46(27.4 \%) \\
19(11.3 \%)\end{array}$ & $\mathrm{P}<0.001$ \\
\hline
\end{tabular}




\section{Discussion}

In our study sample, female subjects were relatively younger than males (median ages 21 vs. 24 years). The female subjects who consumed poison in our study were more educated than the males. $43 \%$ of males had only primary education whereas $82 \%$ of females had gone beyond primary education level. This highlights that the females who consumed poisons were more educated than the males.

A similar observation was made on the analysis of employment, in which $59.5 \%$ of females were currently employed compared to $34.1 \%$ males. This higher level of employment in females may be due to the better education they have received. Majority of males $(51.1 \%)$ were from the lower social class 5 while $43.5 \%$ of females were from the social class 4 . The observed higher level of education and the high percentage of employment in females might explain the difference between the social classes.

Family conflicts and problems related to love affaires were the leading immediate causes of poisoning in both groups in this study. But females outnumbered males in family conflicts (57.1\% vs. $40 \%)$. This probably reflects the higher incidence of family disharmony affecting the females in the society.

Previous studies in Sri Lanka have shown that the choice of poison was more determined by the availability ${ }^{4}$. The type of poison observed in our study also may support the above observation.
Males probably had more access to agrochemicals whereas females chose to takes drugs which were more accessible to them.

The characteristics can be used to identify the vulnerable individuals in the society and to arrange focused social supportive programmes.

The leading immediate cause of poisoning in both sexes was family disharmony emphasizing the importance of community based programmes to improve the family harmony to reduce the burden of self poisoning.

\section{References}

1. Eddleston M. Patterns and problems of deliberate selfpoisoning in the developing world. QJM 2000 Nov, 93(11): 715-31.

2. Hettiarachchi J, Kodithuwakku GC. Self-poisoning in Sri Lanka: factors determining the choice of the poisoning agents. Hum Toxicol 1989 Nov; 8(6): 50710.

3. DJC Barker, G Rose. British classification of social classes. In: Epidemiology in Medical Practice, $3^{\text {rd }}$ edition, Churchill Livingstone, 1984; 63.

4. Eddlestom M, Karunarathne A, Weerakoon M. et al. Choice of poison for intentional self-poisoning in rural Sri Lanka. Clin Toxicol (Phil) 2006; 44(3): 283-6. 